\title{
Perfluorocarbon induces alveolar epithelial cell response through structural and mechanical remodeling
}

\author{
Sofia André Dias ${ }^{1,2} \cdot$ Emmanuelle Planus $^{3} \cdot$ Christelle Angely $^{1} \cdot$ Luc Lotteau $^{2} \cdot$ Renaud Tissier $^{4}$ - Marcel Filoche ${ }^{1,5}$. \\ Bruno Louis ${ }^{1}$. Gabriel Pelle ${ }^{1,6}$. Daniel Isabey ${ }^{1}$ (D)
}

Received: 28 July 2017 / Accepted: 2 February 2018 / Published online: 15 February 2018

(c) The Author(s) 2018. This article is an open access publication

\begin{abstract}
During total liquid ventilation, lung cells are exposed to perfluorocarbon (PFC) whose chemophysical properties highly differ from standard aqueous cell feeding medium (DMEM). We herein perform a systematic study of structural and mechanical properties of A549 alveolar epithelial cells in order to characterize their response to PFC exposure, using DMEM as control condition. Changes in F-actin structure, focal adhesion density and glycocalyx distribution are evaluated by confocal fluorescent microscopy. Changes in cell mechanics and adhesion are measured by multiscale magnetic twisting cytometry (MTC). Two different microrheological models (single Voigt and power law) are used to analyze the cell mechanics characterized by cytoskeleton (CSK) stiffness and characteristic relaxation times. Cell-matrix adhesion is analyzed using a stochastic multibond deadhesion model taking into account the non-reversible character of the cell response, allowing us to quantify the adhesion weakness and the number of associated bonds. The roles of F-actin structure and glycocalyx layer are evaluated by depolymerizing F-actin and degrading glycocalyx, respectively. Results show that PFC exposure consistently induces F-actin remodeling, CSK softening and adhesion weakening. These results demonstrate that PFC triggers an alveolar epithelial cell response herein evidenced by a decay in intracellular CSK tension, an adhesion weakening and a glycocalyx layer redistribution. These PFC-induced cell adjustments are consistent with the hypothesis that cells respond to a decrease in adhesion energy at cell surface. This adhesion energy can be even further reduced in the presence of surfactant adsorbed at the cell surface.
\end{abstract}

Keywords Mechanotransduction $\cdot$ Cytoskeleton $\cdot$ Glycocalyx $\cdot$ Prestress $\cdot$ Surfactant

For this research, we acknowledge receipt of grants from Fondation pour la Recherche Médicale: FRM programme Bio-Ingénierie pour la Santé 2014, DBS 20140930771. Sofia André Dias is a Ph.D. student supported by Agence Nationale de la Recherche et Technologies (ANRT) and Bertin Technologies.

Electronic supplementary material The online version of this article (https://doi.org/10.1007/s10237-018-1005-z) contains supplementary material, which is available to authorized users.

Daniel Isabey

daniel.isabey@inserm.fr

Sofia André Dias

sofia.andredias@airliquide.com

Emmanuelle Planus

emmanuelle.planus@ujf-grenoble.fr

Christelle Angely

christelle.angely@inserm.fr

Luc Lotteau

luc.lotteau@bertin.fr
Renaud Tissier

renaud.tissier@vet-alfort.fr

Marcel Filoche

marcel.filoche@polytechnique.edu

Bruno Louis

bruno.louis@inserm.fr

Gabriel Pelle

gabriel.pelle@inserm.fr

1 Inserm, IMRB, U955, Équipe 13, Biomécanique \& Appareil Respiratoire, Université Paris Est, UMR S955, UPEC, CNRS, ERL 7000, 8, rue du Général Sarrail, 94010 Créteil Cedex, France

2 Bertin Technologies, 78180 Montigny le Bretonneux, France

3 Centre de Recherche, Université Grenoble Alpes, Inserm U1209, CNRS 5309, Grenoble, France 


\section{Introduction}

Perfluorocarbons (PFCs) are fluorinated organic compounds with a great capacity for dissolving high concentration of oxygen and carbon dioxide, making this liquid of interest to perform liquid ventilation (Clark and Gollan 1966). Liquid ventilation has been proposed for a wide range of applications such as bronchial lavage after meconium aspiration (Avoine et al. 2011), induction of ultrafast hypothermia after cardiac arrest for brain tissue protection (Darbera et al. 2013) and improvement of gas exchanges and lung compliance in adults and infants with acute respiratory distress (Hirschl et al. 1995). The peculiar chemophysical properties of this liquid are mostly due to fluorine. PFC is highly electronegative and possesses a low polarization level along with high ionization potential (Kissa 1994), resulting in low van der Waals interactions between fluorinated chains as well as low cohesive energy densities in liquid fluorocarbons (Riess 1994). These reduced interactions make PFC a non-polar liquid of low surface tension with a high spreading coefficient and high gas solubility (Riess and Krafft 1997). Fluorine also promotes an increased hydrophobicity and lipophobicity (Krafft 2001). Carbon-fluorine bonds are among the strongest covalent bonds, making fluorocarbons very stable without known deleterious biological properties, such as toxic, carcinogenic or mutagenic effects (Tooley et al. 1996). The low surface tension and the high spreading power of PFC enable this liquid to distribute uniformly throughout the lung, and permit an easy liquid migration toward gas exchange territories, leading to an improvement of ventilation and a greater lung compliance in liquid ventilation than in air ventilation (Varani et al. 1996).

Among the various applications of PFC, the biological response of cells to PFC exposure is a central question which has rarely been investigated. Cellular studies suggest potential anti-inflammatory effects (Varani et al. 1996) and membrane-related cellular effects (Wemhöner et al. 2010). Yet, to our knowledge, a thorough structural and mechanical assessment of the cell response to PFC exposure is still lacking. By contrast, it is well known that changing either chemical or mechanical properties of basal cellular environment changes cell response by altering cell adhesion and modifying cell stiffness (Féréol et al. 2006). Therefore, one of the main questions raised by PFC exposure is whether

4 Inserm, IMRB, U955, Equipe 03, Université Paris Est, UMRS955, UPEC, Ecole Nationale Vétérinaire d'Alfort, 7 avenue du général de Gaulle, 94700 Maisons-Alfort, France

5 Physique de la Matière Condensée, Ecole Polytechnique, CNRS, 91128 Palaiseau, France

6 APHP, Groupe Hospitalier H. Mondor A. Chenevier, Service des Explorations Fonctionnelles, 51, Avenue du Maréchal de Lattre de Tassigny, 94010 Créteil Cedex, France such a change in environmental conditions from the apical cell face impacts the cell structure, mechanics and adhesion.

To this end, we designed a cellular in vitro study in which A549 cells are exposed to liquid PFC for various durations $(\leq 2 \mathrm{~h})$, while their structural and mechanical properties are systematically evaluated and compared to the cell response obtained with a classical aqueous cell feeding culture medium (DMEM), herein defined as control conditions. In particular, we tested the roles of CSK prestress (by means of F-actin depolymerizing treatment by cytochalasin D (CytoD)) and glycocalyx layer (by means of glycocalyx degradation) which have already been shown to contribute to mechanotransduction as well as to intracellular and transmembrane remodeling in response to stress (Martins and Abairos 2002; Thi et al. 2004; Féréol et al. 2009; Ingber 2008).

The changes in F-actin, focal adhesion and glycocalyx are followed and evaluated using images of fixed living cells stained after exposure either to PFC (PFC-exposed group) or to DMEM (control group). Fluorescence intensity of F-actin and glycocalyx are compared between the two groups. Changes in cell adhesion are monitored by counting the average number of focal adhesions per cell and the size distribution. We use magnetic twisting cytometry (MTC), enhanced to assess simultaneously cell mechanics and cell adhesion from ligand-coated ferromagnetic microbeads. These microbeads mostly bind transmembrane mechanoreceptors which are physically connected to the Factin CSK, as confirmed by a systematic study of the CytoD response. The changes in cell adhesion and CSK mechanics between control and PFC-exposed cells are described using a recently proposed multiscale model (Isabey et al. 2016). This model consists in two parts: first, a two-parameter deadhesion probabilistic model enabling to quantify adhesion strength and clustering and second, a classical microrheological model. This latter model is either taken as a solid-like viscoelastic model (single Voigt element) or alternatively a power law model (infinite series of Voigt elements), from which one can extract CSK stiffness and one or many relaxation times. The origins of cell response (in particular, the role of mechanotransduction pathways) are discussed taking into consideration the significant cellular and molecular remodeling observed under PFC exposure. We identify three components of the cell mechanics which react to the reduction in adhesion energy due to the highly specific (non-polar) properties of PFC: (1) the intracellular structure of F-actin, (2) the transmembrane adhesion receptors (such as integrins) and (3) the glycocalyx layer. Moreover, interfacial energy which measures the energy mismatch at the apical cell surface would normally increase in the presence of PFC (as a consequence of the PFC-induced decrease in adhesion energy, see Supplementary Material SM1). Interestingly, we find that when a surfactant layer is adsorbed at the cell surface, 
the interfacial energy actually vanishes due to the specific physicochemical properties of surfactant, thus exacerbating the cellular effect of PFC.

\section{Materials and methods}

\subsection{Cell culture, PFC exposure and cell viability}

A549 are human alveolar epithelial cells (ATCC) issued from a human lung carcinoma and having the phenotype of alveolar type II epithelial cells. Cells are grown at confluence in DMEM + 10\%FCS, 2 mML-glutamine, $50 \mathrm{IU} / \mathrm{ml}$ penicillin, $50 \mu \mathrm{g} / \mathrm{ml}$ streptomycin, at $5 \% \mathrm{CO}_{2}-95 \%$ air atmosphere. Routine subcultures (passages 89-92) were done at onetwentieth split ratios by incubation with $0.025 \mathrm{~g} / 100 \mathrm{ml}$ trypsin $-0.02 \mathrm{~g} / 100 \mathrm{ml}$ EDTA in calcium- and magnesiumfree PBS for $10 \mathrm{~min}$ at $37^{\circ} \mathrm{C}$. Moreover, A549 cells have been shown to exhibit metabolic and transport properties consistent with type II pulmonary epithelial cells in vivo, and importantly, they do not functionally differentiate in culture to a cell type capable of liquid-phase endocytosis like type I alveolar epithelial cells (Foster et al. 1998). A more recent study has shown that A549 cells still have the ability to form adherent and tight junctions when grown to confluence (Kawkitinarong et al. 2004). Thus, despite limitations inherent in transformed cell lines, A549 cell lines offer many advantages for studying in vitro the pathophysiological response of alveolar epithelial cells (Belete et al. 2010). We exposed confluent monolayer of A549 adherent cells to PFC (perfluoro-N-octan, $\mathrm{F}_{2}$ Chemicals). Preliminary viability tests using trypan blue test, MTT test and wound repair assays were performed in A549 exposed to pure PFC. Note that PFC does not induce cell toxicity but does not contain nutrient, and is not soluble into aqueous liquids such as DMEM (Varani et al. 1996). We find that until $3 \mathrm{~h}$ of cells exposure to the sole PFC, cell viability and cell migration and repair are all comparable to control cell culture medium.

\subsection{Staining of F-actin, focal adhesion and glycocalyx}

A549 epithelial cells are seeded at a density of $8 \times 10^{4}$ over $16 \mathrm{~mm}$ glass coverslides coated with fibronectin at $1.6 \mu \mathrm{g} / \mathrm{cm}^{2}$. DMEM $+10 \%$ FCS medium is replaced by DMEM $+0.5 \%$ BSA the night before the experiments. Cells are exposed $2 \mathrm{~h}$ either to PFC (PFC-exposed group) or to DMEM + 0.5\%BSA (control group). The changes in F-actin network and in focal adhesions are evaluated by quantifying the fluorescence of alexa 543-phalloidin and of antibody against phosphotyrosin PY99 (sc-7020, Santa Cruz Biotechnology) coupled with a secondary antibody Alexa Fluor 488 of paraformaldehyde-fixed cells. For the focal adhesions and
F-actin network analysis, images are acquired on a Pascal 5 confocal microscope (Zeiss) at $63 \times$ magnification. We analyze the phosphotyrosin PY99 staining (a marker of focal adhesion) using a thresholding method and the particle analyzer in ImageJ (W.S. Rasband; NIH, Bethesda, MD; http:// rsbweb.nih.gov/ij/). Coverslides are mounted on a slide with the cell side down in prolong (Thermo Fisher). Glycocalyx distribution is evaluated in live cells by staining glycocalyx using fluorescein isothiocyanate-labeled wheat germ agglutinin (WGA-FITC) at $5 \mu \mathrm{g} / \mathrm{ml}$ incubated for $10 \mathrm{~min}$ at $37^{\circ}$ C, $5 \% \mathrm{CO}_{2}-95 \%$ air atmosphere as in Rai et al. (2015). Images are acquired on fluorescent transmission microscope AxioVert 200 (Zeiss) at 50× magnification. Pixel fluorescence intensities were measured within the entire projected cell area using the basic intensity quantification with the ImageJ software. For each imaging channel, acquisition parameters were fixed for exposure time, excitation intensity, gain and voltages.

\subsection{Measurement of cell response by MTC}

\subsubsection{Culture preparation}

Cells are seeded at a density of $7 \times 10^{4}$ in a 6-mm-diameter circular plastic well coated with fibronectin at $1.6 \mu \mathrm{g} / \mathrm{cm}^{2}$. Confluence was reached after $24 \mathrm{~h}$ of incubation in DMEM $+10 \%$ FCS. DMEM $+10 \%$ FCS medium is replaced by DMEM $+0.5 \%$ BSA the night before the experiments. Cells were exposed to PFC at different times, from $5 \mathrm{~min}$ to $2 \mathrm{~h}$. In surfactant studies, a layer of surfactant is adsorbed at the cell monolayer surface before exposing to PFC or DMEM. A minimal quantity of surfactant, poractant alfa $\left(\right.$ Curosurf $\left.^{\circledR}\right)$, adheres to the cell layer, the excess of this product being removed by aspiration and successive washes. To verify that a thin layer of surfactant remains adherent despite the washes and PFC exposure, the surfactant is made fluorescent using fluorescein (SERB), and its presence is verified under fluorescent microscope. Ferromagnetic beads of $4.5 \mu \mathrm{m}$ diameter (Spherotech) are coated with fibronectin at a concentration of $0.4 \mathrm{mg} / \mathrm{ml}$, fibronectin being a protein mainly recognized by integrins expressed at the cell surface. After the exposure of the cells to different mediums, beads are left to adhere for $30 \mathrm{~min}$ at $37^{\circ} \mathrm{C}, 5 \% \mathrm{CO}_{2}-95 \%$ air incubator. Unbounded beads are washed away with serum-free medium. After cell exposure to PFC at different durations, bead attachment was performed during $30 \mathrm{~min}$ followed by 3 washes. When relevant, cytochalasin D (CytoD, Sigma-Aldrich) was added to the same culture for $20 \mathrm{~min}$ at $10 \mu \mathrm{g} / \mathrm{ml}$ concentration to induce depolymerization of F-actin network, and a new MTC measure was performed to estimate the cell response without and with PFC. By modifying the CSK properties, CytoD allows us to assess the contribution of F-actin CSK to the MTC measurement. Similarly, after cell exposure to PFC for 
different durations and a systematic MTC measure performed after bead attachment, heparinase III (Sigma-Aldrich) at a concentration of $5 \mathrm{mU} / \mathrm{ml}$ was added for $30 \mathrm{~min}$ to the tested cell culture to degrade heparan sulfate of glycocalyx (Yao et al. 2007). Here also, the change in MTC measurement before and after heparinase III treatment allows us to assess the role of glycocalyx on the cell response.

\subsubsection{Principle of MTC}

A549 cell mechanical and adhesion properties are measured by a micromanipulation system through CSK-specific probing, called magnetic twisting cytometry (MTC), which is presented in greater detail in Supplementary Materials SM2. Probes are ferromagnetic microbeads coated with fibronectin. When subject to an external magnetic field, these beads apply a torque to the cell through CSK-specific ligand binding. The relationship between the measured bead rotation angle (angular strain), averaged over the cell culture during cellular loading, and the applied torque provides CSKspecific measurements of adhesion strength and mechanical (rheological) properties (Fig. 1). This technique developed by Wang et al. (1993) has been upgraded by Isabey and co-workers to achieve a multiscale quantification of these parameters (Isabey et al. 2016). Each MTC measurement is performed on a wide number of cells $\left(7 \times 10^{4}\right)$ probed with an even higher number of beads (about twice). The large number of beads and their uniform distribution throughout the cell culture guarantee an instantaneous homogenized cell response, representative of the dominant cell and molecular behaviors (Ohayon et al. 2004). The MTC technique measures the living cell response, accounting for the various phenomena occurring at the cell boundaries: cell-bead, cellmatrix and cell-cell interfaces.

\subsubsection{Modeling the cell microrheology}

There is strong evidence that alveolar epithelial cells are viscoelastic, i.e., they store and dissipate energy (Trepat et al. 2004). Moreover, the mechanical behavior of the adherent cells is governed by the intracellular CSK structure through: (1) the state of tension called "prestress" that is involved in the regulation of cell shape and cell rigidity (Stamenović et al. 1996; Ingber et al. 2014) as well as cell sensitivity to environment (Féréol et al. 2009), (2) the rheological behaviors of multiscale CSK elements that depend on frequency and time of the imposed deformation according to a power law (Equation S9 in SM2), considering that cell mechanics scales over a very broad range of viscoelastic response times (Fabry et al. 2001). In tracking microrheology experiments with probes directly attached to CSK, the exponent of the power law remains small, below 0.25 , and is almost unchanged among cell types and CSK-specific ligand-receptor bindings (Bal-
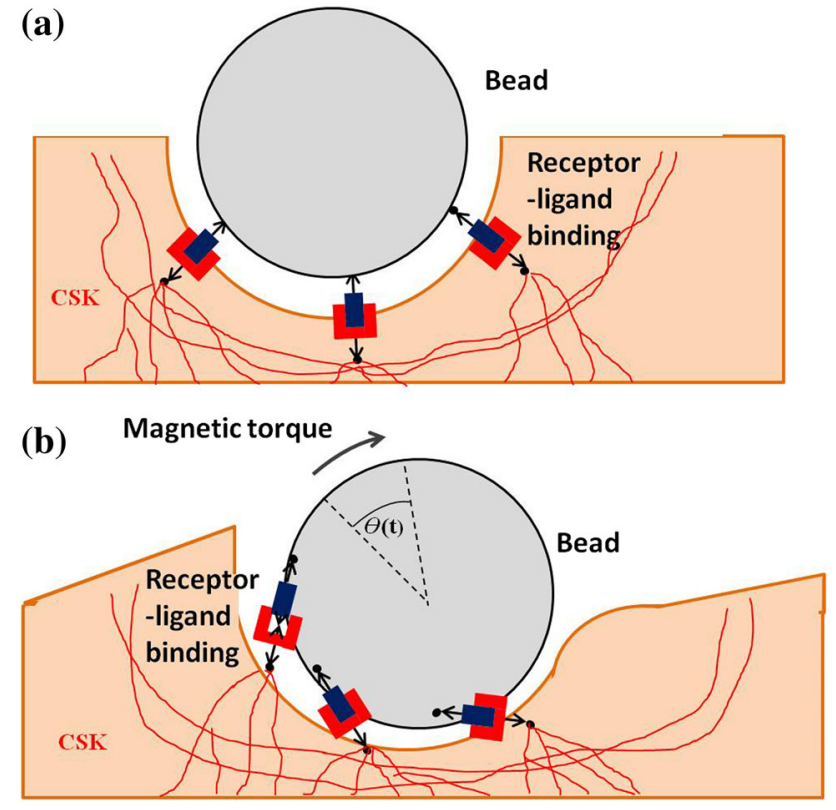

Fig. 1 Schematic representation of an adherent magnetic bead over a cell layer: a before magnetic torque, $\mathbf{b}$ after the MTC magnetic torque. The applied stress causes a rotation and displacement of the bead, and a remodeling of the cell surface CSK configuration. The torque causes a displacement of $\sim 1 \mu \mathrm{m}$ of the receptor-ligand binding for a $4.5-\mu \mathrm{m}$ bead and the rupture of some of these bonds

land et al. 2006). This power law behavior can be modeled by an infinite assembly of Voigt elements having many relaxation times $T_{i}$, taken to be distributed according to a power law $T_{i}=T_{m} i^{-1 /(1-\alpha)}$ with $0<\alpha<1$ and $T_{m}$ being the largest relaxation time in the cell CSK $\left(T_{m}=300 \mathrm{~s}\right.$ in A549 cells) (Balland et al. 2006). The exponent $\alpha$ can be viewed as a transition index between Hookean elastic solid-like $(\alpha=0)$ and Newtonian viscous liquid-like $(\alpha=1)$ behaviors (Fabry et al. 2003). Such association of a large number of elementary Voigt models accounts for the different scales of the CSK network.

The rather low values of $\alpha$ suggests that first, the CSK behavior is closer to an ideal Hookean elastic solid than to an ideal Newtonian viscous fluid, and second, in a limited range of frequencies, the cell mechanical properties can be appropriately provided by a standard viscoelastic solid-like model with only one (or a limited number) of relaxation time(s). In the present study, we use a low-frequency content trapezoidal signal of stress of 1-min duration $(1 / 60 \mathrm{~s} \approx 0.02 \mathrm{~Hz}$, see Figure S1 in SM2) in order to target the quasi-static mechanical behavior of the cell response while avoiding the long-term effects of macroscopic remodeling processes known to interfere with cell mechanical properties (Pathak et al. 2008). We have implemented two alternative models to describe the microrheological cell response to such loading: the single Voigt model (SV model) and the power law model (PL model). In the SV model, two independent parameters are 
used: the cell elastic modulus or CSK stiffness ( $E$ in Pa) whose changes reflect modification of intracellular tension or prestress (Wang et al. 2002) and the viscoelastic relaxation time ( $T$ in s). In the PL model, the cell rheology is characterized by two mechanical parameters: the exponent $\alpha$ and the frequency-dependent complex modulus $G_{e}(\omega)$ whose magnitude $\left|G_{e}\right|$ (in Pa) is usually calculated at an arbitrary $1 \mathrm{~Hz}$ frequency.

\subsubsection{Modeling the cell adhesion}

Independently of the elastic model used for cellular material (linear or nonlinear), mechanical simulations of the stress field demonstrate that stress and strain exhibit spatial heterogeneity and that their maximum values are observed at the cell-bead interface (Féréol et al. 2009; Ohayon et al. 2004). The bonds located at the interface are therefore more susceptible to disruption, which induces deadhesion characterized by a stress-dependent dissociation rate $K_{\mathrm{off}}(\sigma)\left(\mathrm{s}^{-1}\right)$. The non-reversibility of MTC signal (Figure S1 of SM2) and cell deformation (Figure S2 of SM2) is presently considered as a hallmark of this interfacial (although partial) deadhesion (Fig. 1). Beyond the bead-cell interface, the same numerical simulations show that the stress and strain fields generated by magnetic torque rapidly decrease away from the bead (Ohayon et al. 2004; Féréol et al. 2009). The parameters provided by the deadhesion model are, respectively, (1) the natural dissociation rate $K_{\text {off }}(\sigma)\left(\mathrm{s}^{-1}\right)$ and (2) the reference stress $\sigma_{c}(\mathrm{~Pa})$. (In practice, this reference stress is the normalizing factor in the exponential of a generalized Bell model; see SM2.) Theoretically, these two parameters (dissociation rate and reference stress) depend on the distribution of applied forces (Isabey et al. 2013). A change in reference stress may thus reflect either a change in bond configuration or a change in number of bonds (the greater the reference stress, the larger the number of associated bonds). To our knowledge (Ohayon et al. 2004), the direction and magnitude of stress exerted on bonds at the bead-cell interface are clearly three-dimensional, suggesting the dependency of $\sigma_{c}$ with respect to the number of bonds may vary spatially (see SM2).

In summary, a set of 4 parameters is used to describe the multiscale cell mechanical response: two for the microrheological model and two for the deadhesion model. When the SV microrheology model is used, the four parameters are (see SM2): (1) the cell elastic modulus $E$, (2) a typical relaxation time $T$, (3) the natural dissociation rate $K_{\text {off }}$ of the multiple bond system created between bead and cell (which reflects adhesion weakness) and (4) a reference stress $\sigma_{c}$ for the deadhesion process, roughly proportional to the number of associated bonds. When the PL microrheology model is used, the first two parameters are (1) the exponent $\alpha$ of the power law and (2) the norm of the complex viscoelastic modulus $\left|G_{e}\right|$ (see SM2). Both SV and PL models provide an assessment of the CSK stiffness and one (or several) characteristic relaxation time(s).

Both the aforementioned microrheological and the deadhesion models are knowledge and empirically based. These parameters are obtained through best curve fitting with experimental data, according to a least square method based on the Levenberg-Marquardt algorithm, without any priority order in their determination. Data exhibiting a too large level of noise were discarded (about $10 \%$ of all experiments). In all others, the correlation obtained from the fitting procedure was higher than $95 \%$.

\subsection{Statistics}

Data are presented as mean \pm standard deviation for different time conditions within a range of maximum $2 \mathrm{~h}$. To avoid the risk of some history effects on the cell response at a given time condition, experiments at each time condition are performed in new (unstressed) cultures. ' $n$ ' is the number of different cultures used for a given time condition. The standard range of $n$ values is 25-60. Statistical differences between different groups (control and PFC-exposed) are assessed using ANOVA tests. For the analysis of the same group after the action of CytoD or heparinase III, we used Wilcoxon tests. For fluorescent images, the differences between groups are analyzed using Mann-Whitney U tests. For both cell imaging and cellular/molecular mechanics, the number of analyzed cells ' $n$ ' is given in the legend of each figure.

\section{Results}

\subsection{Effect of PFC exposure on F-actin network and cell adhesion structures}

\subsubsection{F-actin remodeling}

Fluorescence of F-actin network was imaged at subconfluence and quantified in control cells and after $2 \mathrm{~h}$ of PFC exposure (Fig. 2a, d). In control conditions, cells exhibit a highly organized and interconnected actin network with a large number of stress fibers, a characteristic pattern in tensed tissue cells. By contrast, after PFC exposure cells exhibit a decrease in F-actin fluorescence intensity and present a less organized stress fiber structure, along with a more rounded shape, consistent with CSK remodeling. A significant decay in fluorescence is measured after PFC exposure (Fig. 2g), confirming the apparent evolution observed on F-actin CSK images in the same conditions. 


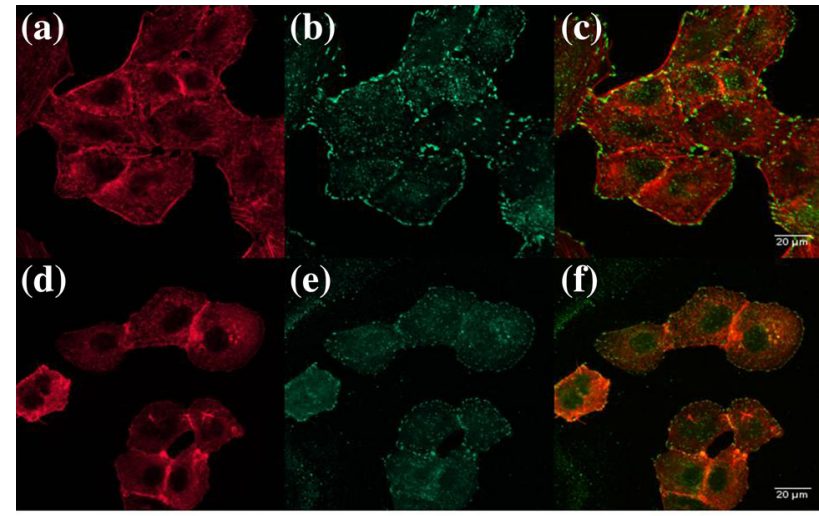

(g)

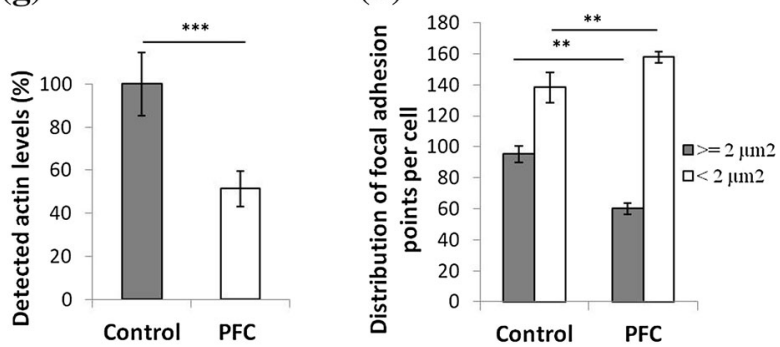

Fig. 2 Co-staining of F-actin (phalloidin, red) and of focal adhesion (phosphotyrosin PY99, green) in fixed subconfluent A549 cells. a, d F-actin staining, b, e focal adhesion staining, $\mathbf{c}, \mathbf{f}$ merge. a-c Control group $(n=49)$, d, f cells after $2 \mathrm{~h}$ of PFC exposure $(n=40) ; n=$ number of cells. $\mathbf{g}$ Quantification of F-actin fluorescence intensity for control group and after PFC exposure. $\mathbf{h}$ Number of focal adhesion points per cell, greater or smaller than $2 \mu \mathrm{m}^{2}$ area for control group and after PFC exposure. F-actin in control cells is highly reticulated and exhibits many stress fibers, as typically observed in tensed tissue cells. After PFC exposure, F-actin is weakened which is confirmed by the significant decay in fluorescent F-actin between control and PFCexposed cells. After PFC exposure, cells acquire a more rounded shape consistent with a smaller internal stress and less stress fibers expressed. The quantification of fluorescence intensity is significantly different between the two groups $(p<0.001)$. Control cells also have numerous large focal adhesions linked to actin stress fibers near the cell periphery and a smaller number in the center. After PFC exposure, focal adhesions at the periphery of the cell are thinner in size and less intense than in control. Results in $\mathbf{h}$ show a significant decrease in the number (per cell) of focal adhesion points greater than $2 \mu \mathrm{m}^{2}$ area after PFC exposure ( $p$ $<0.05)$. Scale bar $20 \mu \mathrm{m}$

\subsubsection{Focal adhesion alteration}

Figure $2 b$, e shows a reduction in the fluorescent phosphotyrosine staining at focal adhesions in subconfluent cells after PFC exposure. This observation is confirmed by the significant decrease in the number (per cell) of focal adhesion points bigger than $2 \mu \mathrm{m}^{2}$ area (Fig. 2h). Thus, PFC exposure induces a loss of focal adhesion points of larger area as observed on the confocal images (Fig. 2b, e) and by the loss in fluorescence of tyrosine phosphorylation (PY99) at the large focal adhesion points. The number of focal adhesions with areas superior or equal to $2 \mu \mathrm{m}_{2}$ decreases by $35 \%$ (Fig. 2h). These observations correlate with the decreases in

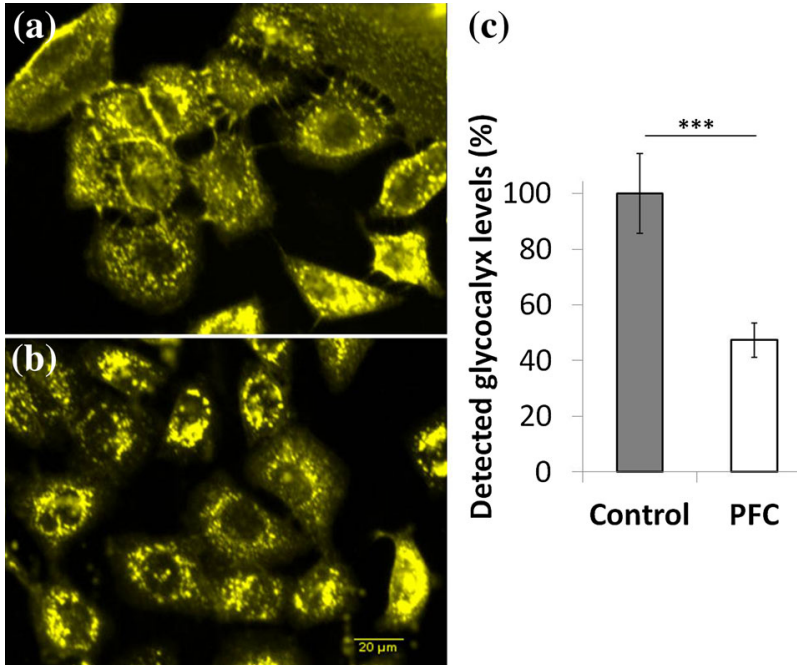

Fig. 3 Glycocalyx staining (WGA-FITC, yellow) of live subconfluent A549 cells a control $(n=37)$, b after 2 h of PFC exposure $(n=61)$, $n=$ number of cells. $\mathbf{c}$ Quantification of glycocalyx by measure of fluorescence for the control and after $2 \mathrm{~h}$ of PFC exposure. Glycocalyx in control cells is more uniformly distributed and largely expressed. Cells after PFC exposure exhibit a decrease in glycocalyx expression and a more peripheral redistribution of glycocalyx as clusters. The fluorescence intensity is significantly different between the two groups $(p<0.001)$. Scale bar $20 \mu \mathrm{m}$

density of F-actin network and stress fibers observed after PFC exposure.

\subsubsection{Glycocalyx redistribution}

We imaged and quantified the fluorescence of glycocalyx stained with WGA-FITC in control group and after $2 \mathrm{~h}$ of PFC exposure (Fig. 3a-c). Cells in control groups express a rather uniform distribution of glycocalyx at the cell surface. After PFC exposure, there is a marked decrease in glycocalyx expression, confirmed by a significant decay in total fluorescence intensity (Fig. 3c), whereas we observe a more peripheral redistribution of glycocalyx as clusters.

\subsection{Effect of PFC exposure on cell mechanical properties and adhesion parameters}

\subsubsection{Effect of different durations of PFC exposure}

Testing different PFC exposure durations, from 5 min to $2 \mathrm{~h}$, reveals that significant changes in the cell mechanical properties occur after $0.5 \mathrm{~h}$ (Figs. 4 and 5). When the SV model is used (Fig. 4a, d), we observe a decrease in time of CSK stiffness, $E$ beyond 0.5 h of PFC exposure, followed by a significant increase in the natural dissociation rate $K_{\text {off }}^{0}$ from $1.5 \mathrm{~h}$. The reference stress $\sigma_{c}$ is also significantly decreased by PFC exposure. Such evolution for $\sigma_{c}$ suggests a reduction in the number of molecular bonds between the bead and the 


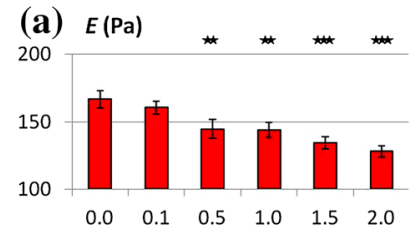

Duration of PFC exposure (h)
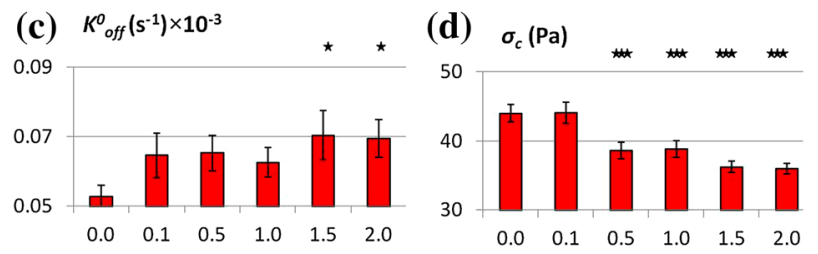

Duration of PFC exposure (h)

Fig. 4 Mean values and SEM of mechanical properties and adhesion parameters, in the viscoelastic solid-like model (SV model), for control conditions $(t=0 \mathrm{~h})$ and after different durations of PFC exposure(from 5 min to $2 \mathrm{~h}$ ) in confluent A549 cells. Parameters of SV model are: a cell elastic modulus or CSK stiffness $E$ in $\mathrm{Pa}$, $\mathbf{b}$ viscoelastic relaxation time $T$ in s, c natural dissociation rate $K_{\mathrm{off}}^{0}$ in s$^{-1}$, a marker of adhesion weakness (d) reference stress $\sigma_{c}$ in Pa reflecting the number of adhesion bonds. The differences between the control group and PFC-exposed are analyzed using ANOVA tests (the number of stars quantifies the significance compared to the measured value in control condition, ${ }^{* * *} p$ $<0.001 ; * * p<0.01 ; * p<0.05) . n_{\text {Control }}=59, n_{0.1 \mathrm{~h}}=33, n_{0.5 \mathrm{~h}}=36$, $n_{1.0 \mathrm{~h}}=40, n_{1.5 \mathrm{~h}}=29, n_{2 h}=68$

cell. All these results obtained using the SV model depict a marked change in cell behavior in response to PFC exposure. This PFC-induced cell response is characterized by cell softening and adhesion weakening in these confluent A549 cells.

When the PL model is used, a similar trend is observed for the mechanical properties: $\left|G_{e}\right|$ values decrease significantly, consistently with the evolution found for the SV model, confirming that both rheological models provide similar mechanical information (Fig. 5b). The real part of the complex modulus (PL model) recalculated at the fundamental MTC frequency $(0.02 \mathrm{~Hz})$ exhibits values and evolution which are similar to $E$ (SV model, results not shown). The evolution of the parameter $\alpha$ is characterized by a significant increase. However, $\alpha$-values never exceed 0.13 (instead of $\alpha=0.11$ in control conditions). Although such increase is too modest to indicate a net fluidization process, it yet suggests a change in cell behavior in response to PFC exposure. In contrast to the $\mathrm{SV}$ model, the adhesion parameters $K_{\text {off }}^{0}$ and $\sigma_{c}$ (Fig. 5c, d) obtained when the PL model is used remain unaffected by PFC exposure. In addition, the values found for $K_{\text {off }}^{0}$ using the PL model are one order of magnitude smaller than those obtained using the SV model. This suggests that the PL model, which satisfactorily describes mechanical evolutions as well as the SV model, is not able to account for the focal adhesion alterations revealed by the fluorescent images. By contrast, the use of the SV model satisfactorily describes
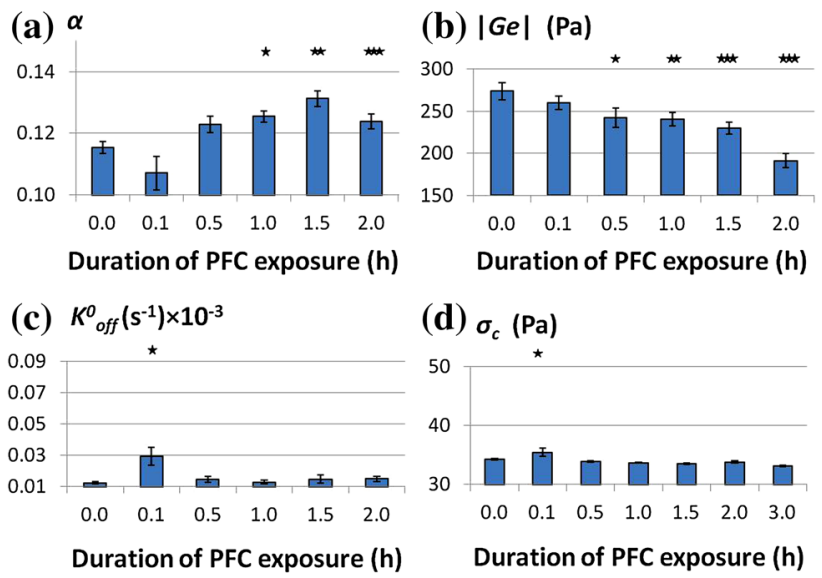

Fig. 5 Mean values and SEM of mechanical properties and adhesion parameters, in the PL model, for control conditions $(t=0 \mathrm{~h})$ and after different duration of PFC exposure (from $5 \mathrm{~min}$ to $2 \mathrm{~h}$ ) in confluent A549 cells. Parameters of the PL model are: a exponent of the power law: $\alpha$, b norm of the complex modulus: $\left|G_{e}\right|$ at $f=1 \mathrm{~Hz}$ in $\mathrm{Pa}, \mathbf{c}$ natural dissociation rate $K_{\text {off }}^{0}$ in s ${ }^{-1}$, a marker of adhesion weakness, $\mathbf{d}$ reference stress $\sigma_{c}$ in Pa reflecting the number of adhesion bonds. The differences between the control group and PFC-exposed are analyzed using ANOVA tests (the number of stars quantifies the significance compared to the measured value in control condition, $* * * p<0.001$; $* * p<0.01 ; * p<0.05) . n_{\text {Control }}=59, n_{0.1 \mathrm{~h}}=33, n_{0.5 \mathrm{~h}}=36$, $n_{1.0 \mathrm{~h}}=40, n_{1.5 \mathrm{~h}}=29, n_{2 \mathrm{~h}}=68$

both the mechanical and the cell adhesion changes induced by PFC exposure.

\subsubsection{Effect of F-actin depolymerization on cell response}

Both control and PFC-exposed groups were treated by CytoD after each MTC experiment in order to confirm the actin CSK specificity of the cell response. Two significant parameters of the studied cell response are presented in Fig. 6, namely $E$ and $\left|G_{e}\right|$. Their observed discrepancies with and without CytoD treatment are all highly significant. Depolymerizing F-actin filaments with CytoD results in a largely documented CSK weakening process that reveals the contribution of intracellular tension (cell prestress) to cellular stiffness (Wang et al. 2002). Mechanical properties measured in treated cells before and after PFC exposure demonstrate a cell stiffness level identical to the control level for all exposure durations. In other words, once the contribution of actin stress fibers is removed by CytoD treatment, cell stiffness in PFC-exposed group becomes independent of PFC exposure. These results suggest that intracellular tension plays a key role in the cell response to PFC exposure.

\subsubsection{Effect of glycocalyx degradation on cell response}

Heparinase III is used to degrade heparan sulfate, the most abundant component of glycocalyx, while monitoring the mechanical and adhesion parameters. Both cells in control 


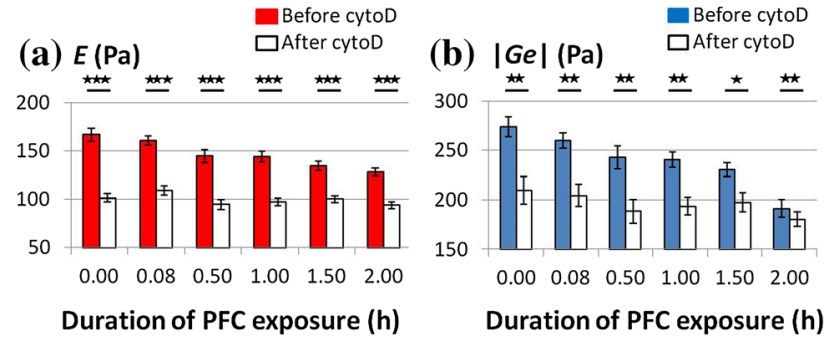

Fig. 6 Effect of CytoD treatment (before, in red, and after, in white, CytoD treatment) on CSK stiffness $E$ (from SV model) in a and $\left|G_{e}\right|$ (from PL model) in $\mathbf{b}$, for control $(t=0 \mathrm{~h}$ ) and after various durations of PFC exposure (from $5 \mathrm{~min}$ to $2 \mathrm{~h}$ ). The differences observed between data obtained before and after CytoD treatment are analyzed on the same group of cells exposed for each given duration to PFC exposure ( $n$ : number of cells) using Wilcoxon tests $(* * * p<0.001, * * p<0.01$;). $n_{\text {Control }}=59, n_{0.1 \mathrm{~h}}=33, n_{0.5 \mathrm{~h}}=36, n 1.0 \mathrm{~h}=40, n_{1.5 \mathrm{~h}}=29$, $n_{2.0 \mathrm{~h}}=68$
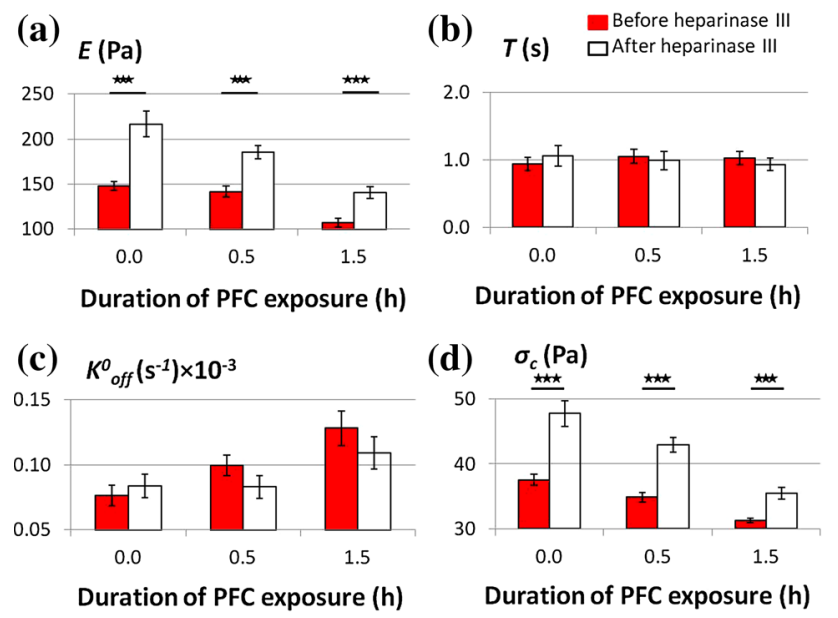

Fig. 7 Effect of glycocalyx degradation by heparinase III. Mean values and SEM of mechanical properties and adhesion parameters are given for control condition $(t=0 \mathrm{~h})$ and after two durations of PFC exposure $(0.5$ and $1.5 \mathrm{~h})$ before - in red - and after - in white - glycocalyx degradation. Parameters of the viscoelastic solid-like model with adhesion parameters (SV, in red): a cell elastic modulus or CSK stiffness $E$ in $\mathrm{Pa}$, b viscoelastic relaxation time $T$ in s, c natural dissociation rate $K_{\text {off }}^{0}$ in $\mathrm{s}^{-1}$ quantifying adhesion weakness, $\mathbf{d}$ reference stress $\sigma_{c}$ in Pa reflecting the number of bonds associated. The differences observed between data obtained before and after heparinase III treatment are analyzed in the same group of cells ( $n$ : number of cells) before and after glycocalyx degradation $(* * * p<0.001 ; * * p<0.01 ; * p<0.05) . n_{\text {Control }}=25$, $n_{0.5 \mathrm{~h}}=31 ; n_{1.5 \mathrm{~h}}=31$

conditions and cells exposed to PFC for $0.5 \mathrm{~h}$ and $1.5 \mathrm{~h}$ were treated with heparinase III, and results obtained for each duration were compared before and after CytoD treatment. The two rheological models (SV and PL) show that cells of the control group do not behave like cells of the PFC-exposed group (Figs. 7a and 8b). In particular, cells whose glycocalyx is degraded are systematically and significantly rigidified, and express a more marked response to PFC exposure than cells with non-degraded glycocalyx. Similarly,
Before heparinase II $\square$ After heparinase III

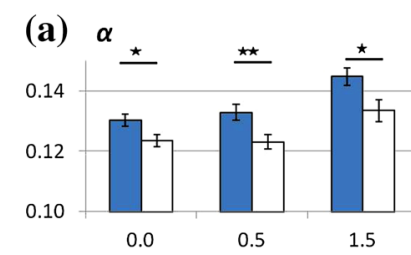

Duration of PFC exposure (h)

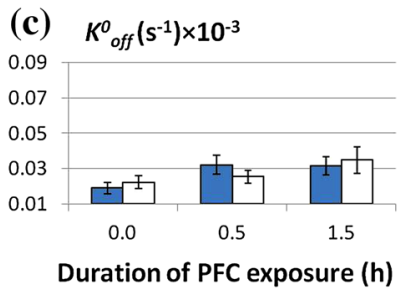

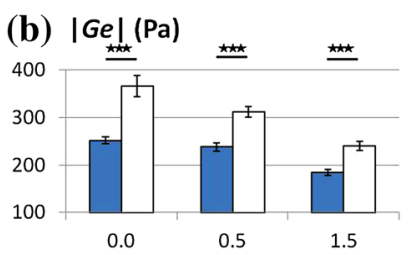

Duration of PFC exposure (h)

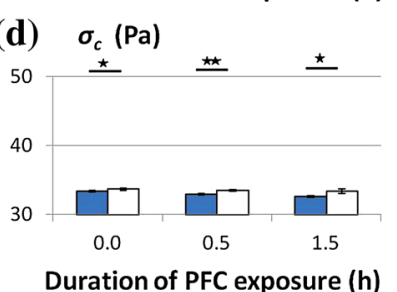

Fig. 8 Effect of glycocalyx degradation by heparinase III. Mean values and SEM of mechanical properties and adhesion parameters are given for control condition $(t=0 \mathrm{~h})$ and after two durations of PFC exposure $(0.5$ and $1.5 \mathrm{~h})$ before — in blue — and after-in white — glycocalyx degradation. Parameters of the power law with adhesion model (PL, in blue): a exponent of the power law: $\alpha$, b norm of the complex modulus: $\left|G_{e}\right|$ at $f=1 \mathrm{~Hz}$ in $\mathrm{Pa}$, c natural dissociation rate in $\mathrm{s}^{-1}$ quantifying adhesion weakness, $\mathbf{d}$ reference stress $\sigma_{c}$ in Pa reflecting the number of associated adhesion bonds. The differences observed between data obtained before and after heparinase III treatment are analyzed in the same group of cells ( $n$ : number of cells) before and after glycocalyx degradation using Wilcoxon tests $(* * * p<0.001 ; * * p<0.01 ; * p<0.05)$. $n_{\text {Control }}=25, n_{0.5 \mathrm{~h}}=31 ; n_{1.5 \mathrm{~h}}=31$

adhesion parameters obtained with the SV model exhibit a stabilization of adhesion (Fig. 7) and a more marked adhesion remodeling after PFC exposure in heparinase-treated cells than in non-treated cells (Fig. 7). These results suggest that glycocalyx layer regulates the cell response to PFC exposure. The precise reasons behind the stiffening and adhesion stabilization phenomena in glycocalyx degraded cells remain to be elucidated. We presently consider that the time left to observe apoptotic effects induced by glycocalyx degradation is too short (about $30 \mathrm{~min}$, see Materials and methods) (Rai et al. 2015). Interestingly, the PL model reflects the mechanical effect depicted above, but not the totality of adhesion effect observed in glycocalyx degraded cells after PFC exposure. Indeed, only the use of the SV model shows an apparent reinforcement in cell adhesion ( $K_{\text {off }}^{0}$ is slightly decreased) and an increase in cell-matrix interactions through the increase in the number of associated adhesion bonds ( $\sigma_{c}$ is increased). These results suggest a specific role of the glycocalyx layer in the cell response to PFC exposure. As an interfacial mechanosensitive structure, it seems logical that the cell surface contributes to the regulation of the cell response to PFC exposure. 


\subsubsection{Effect of intercalating a surfactant layer on cell response to PFC}

In vivo, the epithelial glycocalyx and the surfactant form together a lining layer at the surface of alveolar epithelium which plays the role of a mechanotransductor. Pulmonary surfactant, normally produced by type II alveolar cells, is known to reduce surface tension at the interface between alveolar wall and air (Bernhard et al. 2000). However, A549 alveolar epithelial cells do not produce surfactant under cell culture condition (Swain et al. 2010). To better mimic the physiology of the alveolar cell monolayer surface, surfactant was preliminary deposited by adsorption on the cell layer surface (see Materials and methods). The effect of intercalating such a surfactant layer between the cell and the apical liquid (DMEM or PFC) most likely modifies the surface tension of the cell layer (see SM1). The cellular effect of intercalating such a surfactant layer was studied for the two mediums, DMEM and PFC, and at two exposure durations, namely $0.5 \mathrm{~h}$ and $1.5 \mathrm{~h}$. Evolutions of measured mechanical and adhesion parameters are analyzed by comparison with the control condition $(\mathrm{t}=0)$ in which no surfactant layer is intercalated (Figs. 9 and 10). The presence of surfactant adsorbed at cell surface seems to enhance the cell response to PFC since we observed highly significant decrease in CSK stiffness for the two durations of exposure tested $\left(E\right.$ or $\left.\left|G_{e}\right|\right)$. By contrast, the presence of surfactant does not modify the response of cells exposed to DMEM (Figs. 9a and 10b). Regarding adhesion parameters, we observe-when the multiscale model integrating the SV model is used-a marked increase in $K_{\text {off }}^{0}$ at $1.5 \mathrm{~h}$ of exposure duration to PFC with a significant decay in $\sigma_{c}$, consistent with a smaller number of associated bonds (Fig. 9c, d). By contrast, the PL model is not able to reveal these evolutions of adhesion since the increase in $K_{\text {off }}^{0}$ is not significant. Altogether, the present results reveal that the presence of a surfactant layer adsorbed on cell surface enhances the cell response to PFC: Cell stiffness is decreased, and cell adhesion is weakened - while with DMEM as liquid medium, the same presence of surfactant does not modify significantly cell mechanical and adhesion properties obtained without surfactant. Beyond the possibility of some dilution of aqueous surfactant molecules in the DMEM, present cellular results suggest a less beneficial role of surfactant in the presence of an aqueous medium and a marked beneficial effect of surfactant when PFC is used.

\section{Discussion}

In the present study, we use fluorescent imaging and a CSKspecific micromanipulation method (MTC) directed toward both the intracellular structure (the CSK) and the related cell surface receptors (adhesion receptors). These methods (a) $E$ (Pa)

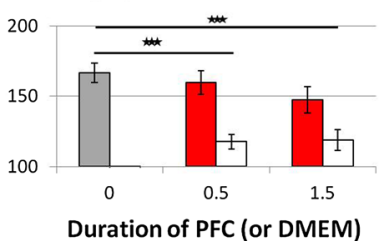

exposure with a surfactant layer $(h)$

(c) $\kappa^{0}{ }_{\text {off }}\left(s^{-1}\right) \times 10^{-3}$

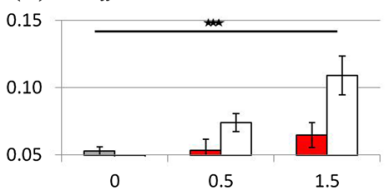

Duration of PFC (or DMEM)

exposure with a surfactant layer $(\mathrm{h})$

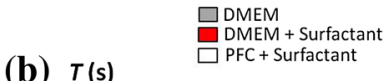

(b) $T(\mathbf{s})$

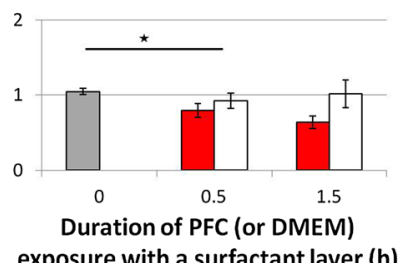

Duration of PFC (or DMEM)

(d) $\sigma_{c}(\mathrm{~Pa})$

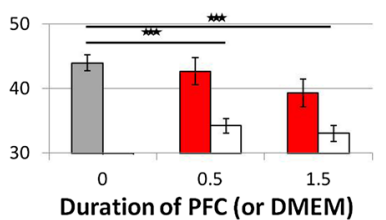

exposure with a surfactant layer (h)
Fig. 9 Effect of intercalating a surfactant layer between cell surface and PFC or DMEM. The mean values and SEM of CSK mechanical properties and adhesion parameters are given for control condition without surfactant (in gray) $(t=0 \mathrm{~h})$, and after two durations $(0.5$ and $1.5 \mathrm{~h})$ of exposure to either PFC (in red) or DMEM (in white), whereas surfactant is adsorbed on cell surface. Parameters of the viscoelastic solid-like model with adhesion parameters: a elastic modulus or CSK stiffness $E$ in $\mathrm{Pa}, \mathbf{b}$ viscoelastic relaxation time $T$ in $\mathrm{s}$, $\mathbf{c}$ natural dissociation rate $K_{\text {off }}^{0}$ in $\mathrm{s}^{-1}, \mathbf{d}$ reference stress $\sigma_{c}$ in Pa reflecting the number of associated adhesion bonds. The differences between the control group and the cells with a surfactant layer are analyzed using ANOVA tests $(* * * p$ $\left.<0.001 *^{* *} p<0.01{ }^{*} p<0.05\right) . n_{\text {Control=DMEM(without Surfactant) }}=59$, $n_{\text {DMEM }+ \text { Surfactant } 0.5 \mathrm{~h}}=20, n_{\text {DMEM }+ \text { Surfactant } 1.5 \mathrm{~h}}=15, n_{\mathrm{PFC} 0.5 \mathrm{~h}}=$ $22, n_{\mathrm{PFC} 1.5 \mathrm{~h}}=17$

enable to quantify the changes in structure, mechanics and adhesion of alveolar epithelial cells after exposure to liquid PFC whose physicochemical properties are quite unusual. The important message provided by the present results is that cellular and molecular parameters measured in cells exposed to PFC exhibit marked differences from control cells which are cultured in a standard liquid medium (DMEM). Given the short duration of PFC exposure $(\leq 1.5 \mathrm{~h})$, cell damage due, e.g., to the lack of nutriment cannot be the cause of the observed cell response. Compared to control, we found no change in cell viability up to $3 \mathrm{~h}$ of PFC exposure. The most likely mechanism revealed by the present results is that confluent or subconfluent alveolar epithelial cells respond to the specific apical environment generated by PFC by remodeling their structure, reducing their internal tension and weakening their adhesion. To our knowledge, such PFC-induced cellular and molecular effects have never been reported in the literature. Incidentally, the period of fetal development supposes a liquid filled lung with epithelial cells continuously exposed to an aqueous liquid interface, meaning that the liquid filled lung is registered in the history of lung development.

These results question the signaling mechanisms involved in the cell response. Two complementary signaling systems are presently identified for their role played in the cell 

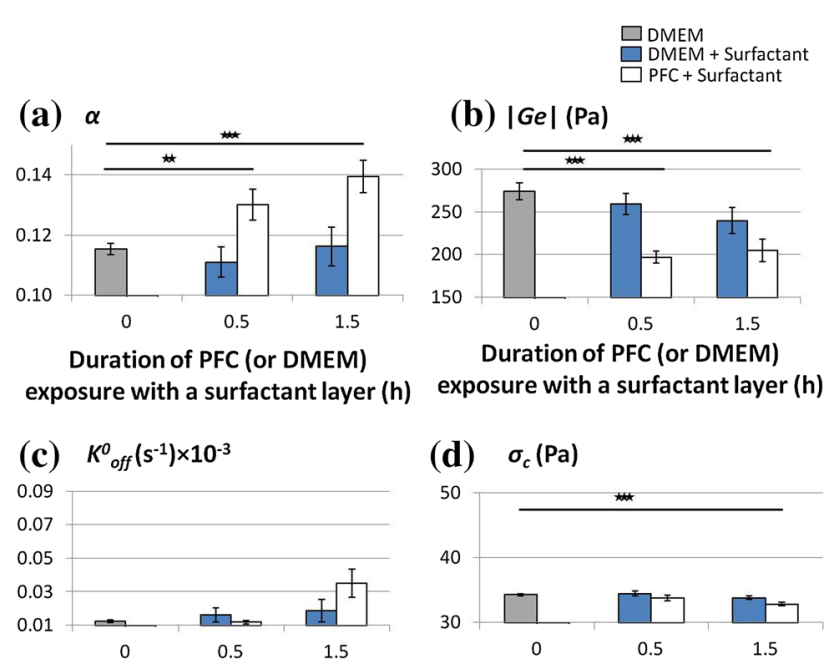

Fig. 10 Effect of intercalating a surfactant layer between cell surface and PFC or DMEM. The mean values and SEM of CSK mechanical properties and adhesion parameters are given for control condition without surfactant (in gray) $(t=0 \mathrm{~h})$ and after two durations $(0.5$ and $1.5 \mathrm{~h}$ ) of exposures to either PFC (in blue) or DMEM (in white), whereas surfactant is adsorbed on cell surface. Parameters of the power law with adhesion model: a exponent of the power law: $\alpha, \mathbf{b}$ norm of the complex modulus: $\left|G_{e}\right|$ at $f=1 \mathrm{~Hz}$ in $\mathrm{Pa}$, c natural dissociation rate $K_{\text {off }}^{0}$ in $\mathrm{s}^{-1}$ quantifying adhesion weakness, $\mathbf{d}$ reference stress $\sigma_{c}$ in Pa reflecting the number of associated adhesion bonds. The differences between the control group and the cells with a surfactant layer are analyzed using ANOVA tests $(* * * p<0.001 ; * * p<$ $0.01 ; *<<0.05) . n_{\text {Control }=\text { DMEM }}=59, n_{D M E M}+$ surfactant $0.5 h=20$, $n_{\text {DMEM }+ \text { surfactant } 1.5 \mathrm{~h}}=15, n_{\mathrm{PFC} 0.5 \mathrm{~h}}=22, n_{P F C 1.5 \mathrm{~h}}=17$

response, although we presume that they are not the only ones. This opens the road for future studies. One of these systems is the intracellular tensed actin structure which has already been proven to play a key role in mechanotransduction (Wang et al. 1993; Ingber 2008). The other is the membranous glycocalyx layer which is known to play a role on the shear stress response of endothelial cells (Yao et al. 2007) and is also present in alveolar epithelial cells (Martins and Abairos 2002). These two structures, F-actin and glycocalyx layer, are physically connected as they contribute together to the cell regulation (Thi et al. 2004). Both structures are of significance in the cell response to PFC exposure: (1) the large decay in $E$ or $\left|G_{e}\right|$ observed after depolymerizing treatment (Fig. 6) confirms the contribution of F-actin-network to cell stiffness and the role of cell prestress; (2) similarly, when the glycocalyx layer is degraded by heparinase III, the cell response to PFC exposure is more marked, suggesting a regulating role of the glycocalyx layer in the cell response to PFC (Figs. 7 and 8). These results are consistent with cell observation and intensity analysis showing peripheral redistribution of glycocalyx through clustering (Fig. 3). They strongly suggest that the glycocalyx layer at cell membrane and the tensed F-actin structure are two pos- sible (among others) key components of the cell signaling pathways involved during PFC exposure.

Imaging F-actin structure and focal adhesion reveals that PFC exposure results in alterations of structural organization through F-actin remodeling, a decrease in the number of larger focal adhesion sites and redistribution of glycocalyx (Figs. 2 and 3). The decay in fluorescent F-actin intensity and the vanishing of stress fibers are consistent with the decay in cell stiffness measured by MTC and predicted by the two different microrheological models (SV and PL). However, the loss in adhesion stability (or loss in adhesion strength) of PFC-exposed cells, visible in the reduction in number and size of focal adhesions, is only predicted by the SV model. The PL model, which assumes a broad power law distribution of relaxation times or characteristic frequencies (Balland et al. 2006), fails to provide significant information concerning the deadhesion phenomenon. It seems that describing the multiscale nature of a cellular material through an infinite series of solid-like elementary Voigt models necessarily assumes that the irreversibility of the cell response is actually due to the largest response time in the CSK network. This time range would be as large as [5-60 min], depending on the cell type, and can thus only be obtained by extrapolation (Balland et al. 2006) meaning that the partial fluidic nature of living cells is simply guessed as it cannot be reliably measured experimentally due to the interaction with biological remodeling. Interestingly, CSK softening (see Figs. 5b, $8 \mathrm{~b}, 10 \mathrm{~b}$ ) is often associated with fluidization as shown by the discrete increase in the exponent $\alpha$ (see Figs. 5a, 8a, 10a). Since only the SV model provides significant evolution of adhesion parameters consistent with the staining images of adhesion, we considered the SV model as the most powerful for describing in the low-frequency range the cell response evolution.

Different physicochemical factors related to the highly specific properties of PFC might play a role in the cell response to PFC exposure. First, the high density and dynamic viscosity (Wesseler et al. 1977) do not play a role because alveolar epithelial cells are tested in static conditions, relevant for reproducing the physiological conditions experienced by cells in alveolar territories (André Dias et al. 2015). Secondly, the large quantity of $\mathrm{O}_{2}$ dissolved in PFC at normal atmospheric pressure (Wesseler et al. 1977) could be seen as a mild hyperoxic condition and thus play a role in the modulation of functional, mechanical and adhesive properties (Sen 2009). We performed the same evaluation of parameters in severe hypoxia $\left(1 \%\right.$ of $\left.\mathrm{O}_{2}\right)$ condition and found that alveolar epithelial cell properties were not modified (data not shown), suggesting that the larger amount of $\mathrm{O}_{2}$ dissolved in $\mathrm{PFC}$ in present experimental conditions does not account for the observed PFC-induced cell response.

Another PFC property that could be responsible for the reported cell response is the low surface tension of this liq- 
uid (see SM1), whether a surfactant layer is added or not at the apical cell surface. The question which remains to be answered concerns the evolution of the energy perceived by the cells when a liquid of low surface tension is used. The cell response to tensional changes at cell surface, experimentally evidenced for the first time in this study, suggests that cells experience a decrease in adhesion energy, while interfacial energy also changes and possibly vanishes (see Table $\mathrm{S} 1$ in SM1). We performed a thorough analysis of the new energy balance (Equation S1 in SM1) arising from the exposure of the cell monolayer to PFC. The new interface is composed of an apical cell surface, characterized by both hydrophilic and hydrophobic components, and a non-polar liquid, characterized by a low surface tension (Fig. 11). The lack of polar component of PFC creates an energy mismatch with the cell monolayer which still has polar and non-polar components. Therefore, the cell-PFC interfacial energy which characterizes this mismatch is increased and thus might contribute to the observed cell response (see SM1).

The assumption of a dominant role of surface tension in the cell response is consistent with the results obtained when an exogenous surfactant layer is deposited at the apical cell surface. Indeed, the presence of a surfactant layer appears to amplify the cellular effects reported with PFC alone (Figs. 9 and 10). Intercalating a surfactant layer at the interface between the cell surface and PFC further decreases adhesion energy (see Equation S3 and Table S1 in SM1). One could think that this decrease in adhesion energy would result in an increase in the interfacial energy between the surfactant-coated cells and PFC (through the Dupré equation, Equation S1 in SM1). Surprisingly, this is not the case due to the specific properties of surfactant whose polar ends attach to the cell membrane, while the non-polar ends point toward PFC (see Fig. 11b). The present study shows that this altered mismatch between the two phases at the alveolar interface is experienced by the cells which respond in two ways: internally, by remodeling CSK, which results in a decrease in internal stiffness, and at the interface, by a weakening in cell adhesion and redistribution of glycocalyx. Future studies are required to elucidate the numerous cellular and molecular systems expressing a sensitivity to changes in adhesion energy and/or interfacial energy.

When intercalated between the cell and DMEM (control case, see Fig. 11a), surfactant has a similar effect except that a fraction of the surfactant molecules initially present at the apical cell face might be progressively diluted into the aqueous DMEM medium. Indeed, we observe in Figs. 9 and 10a nonsignificant cellular effect in aqueous conditions (DMEM + surfactant) related to the more modest decrease in adhesion energy than expected without dilution (see the case Surfactant/DMEM versus the case surfactant/PFC in Table S1). Another important effect of surfactant appearing in Table S1 (SM1) concerns the value of interfacial energy which

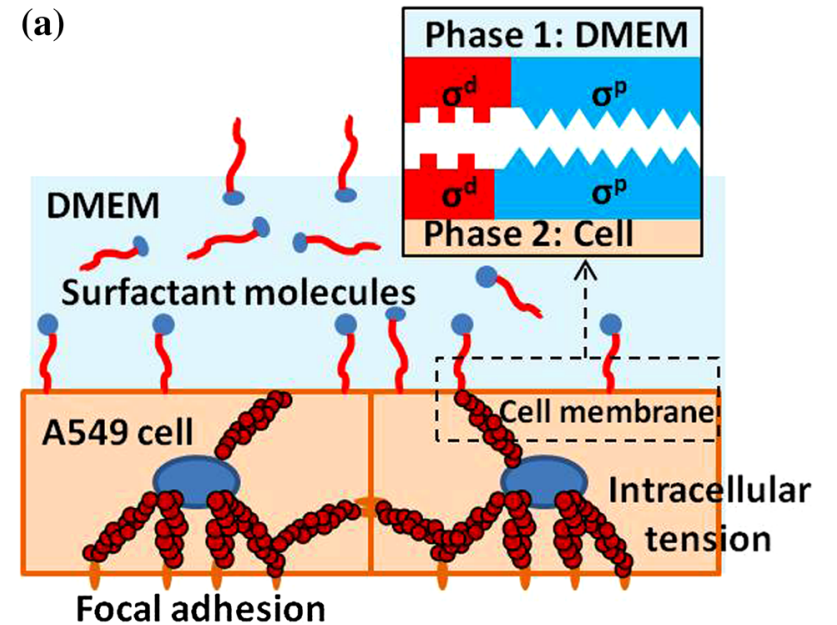

(b)

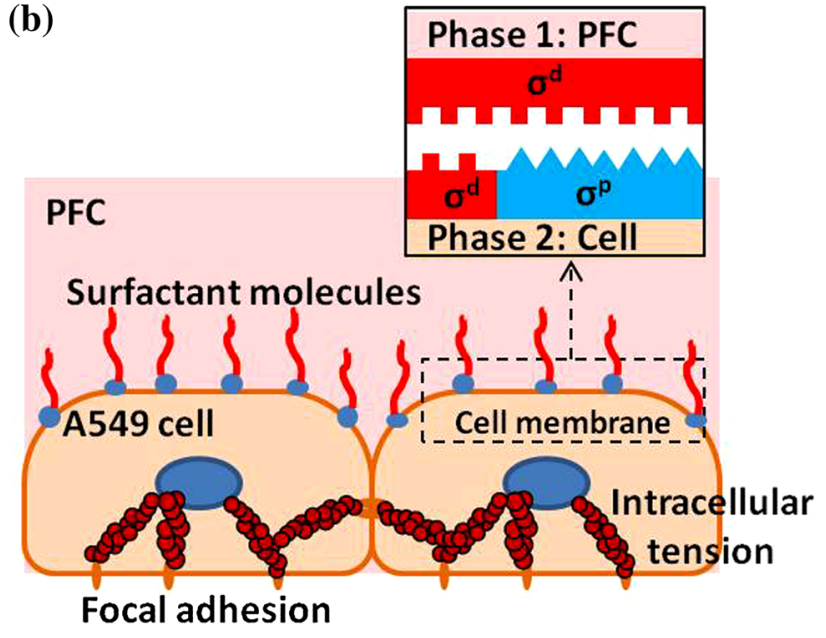

Fig. 11 Schematic configuration of A549 cells with F-actin network: a control with surfactant adsorbed on cell surface, b during PFC exposure with surfactant adsorbed on cell surface. Upper rectangles represent the matching/mismatching between non-polar component (red square notches) and polar component (blue triangular notches). $\sigma^{d}$ : non-polar component, $\sigma^{p}$ : polar component. For control condition with or without surfactant, there is perfect matching between the polar liquid DMEM and the polar cell surface; thus, adhesion energy is elevated. The surfactant creates a thin film that covers the cellular layer. Some surfactant molecules are diluted in DMEM, thus decreasing the surfactant concentration at cell surface. For PFC condition without surfactant, there is only a partial matching between the non-polar PFC and the polar cell surface, resulting in a decrease in adhesion energy (see Table S1 in SM1). However, the mismatch between energetic components causes an increase in cell-PFC interfacial energy, inducing a specific cell response. When a surfactant layer is adsorbed on cell surface, the interfacial energy is drastically reduced instead of being increased (see text and Supplementary Materials SM1 for explanations)

vanishes at the surfactant-PFC interface, while it is above zero in the other cases. Thus, the surfactant layer which is still present when PFC fills the lung (Wemhöner et al. 2010) should have a favorable effect on the PFC-alveolar cell interface. 
In conclusion, using PFC as alveolar environment promotes marked structural, mechanical and adhesion changes in the alveolar epithelial cell response. We notably observed a decrease in internal tension, adhesion weakening as well as redistribution and partial diminution of glycocalyx expression. Therefore, the CSK and the glycocalyx layer appear as key elements of mechanotransduction, but other mechanosensitive elements which remain to be studied could also play a role at many various scales. The presently reported PFC-induced cellular effects are interpreted as hallmark of the cell response in front of a decrease in adhesion energy at cell membrane.

Acknowledgements The authors thank Claude Danan for the surfactant, Emilie Béquignon, Gilbert Desmarais, Ngoc-Minh Nguyen and Sylvain Millemann for their helpful advice, and to Ira Katz for proofreading the article.

Author contributions S.A.D. designed and performed experiments, analyzed data and wrote the paper; E.P designed experiments and gave technical support and conceptual advice; C.A performed experiments; B.L and G.P. developed analytical tools, analyzed data and supervised the project; R.T. and L.L. gave conceptual advice and provided technical expertise; M.F. gave conceptual advice and wrote the paper; D.I. designed the study, supervised the project and wrote the paper. All authors gave final approval for publication.

\section{Compliance with ethical standards}

Conflicts of interest All authors declare that they have no conflict of interest.

Open Access This article is distributed under the terms of the Creative Commons Attribution 4.0 International License (http://creativecomm ons.org/licenses/by/4.0/), which permits unrestricted use, distribution, and reproduction in any medium, provided you give appropriate credit to the original author(s) and the source, provide a link to the Creative Commons license, and indicate if changes were made.

\section{References}

André Dias S, Berdeaux A, Darrasse L, Demanesse M, de Rochefort L, Filoche M, Ghaleh B, Hutin A, Isabey D, Kunc T et al (2015) ABYSS: therapeutic hypothermia by total liquid ventilation following cardiac arrest and resuscitation. IRBM 36:110-117. https:// doi.org/10.1016/j.irbm.2015.01.011

Avoine O, Bosse D, Beaudry B, Beaulieu A, Albadine R, Praud JP, Robert R, Micheau P, Walti H (2011) Total liquid ventilation efficacy in an ovine model of severe meconium aspiration syndrome. Crit Care Med 39:1097-1103. https://doi.org/10.1097/ CCM.0b013e31820ead1a

Balland M, Desprat N, Icard D, Féréol S, Asnacios A, Browaeys J, Henon S, Gallet F (2006) Power laws in microrheology experiments on living cells: comparative analysis and modeling. Phys Rev E Stat Nonlinear Softw Matter Phys 74:021911. https://doi. org/10.1103/PhysRevE.74.021911

Belete HA, Godin LM, Stroetz RW, Hubmayr RD (2010) Experimental models to study cell wounding and repair. Cell Physiol Biochem Int J Exp Cell Physiol Biochem Pharmacol 25:71-80. https://doi. org/10.1159/000272052
Bernhard W, Mottaghian J, Gebert A, Rau GA, von Der HH, Poets CF (2000) Commercial versus native surfactants. Surface activity, molecular components, and the effect of calcium. Am J Respir Crit Care Med 162:1524-1533. https://doi.org/10.1164/ajrccm.162.4. 9908104

Clark LC Jr, Gollan F (1966) Survival of mammals breathing organic liquids equilibrated with oxygen at atmospheric pressure. Science 152:1755-1756

Darbera L, Chenoune M, Lidouren F, Kohlhauer M, Adam C, Bruneval P, Ghaleh B, Dubois-Rande JL, Carli P, Vivien B et al (2013) Hypothermic liquid ventilation prevents early hemodynamic dysfunction and cardiovascular mortality after coronary artery occlusion complicated by cardiac arrest in rabbits. Crit Care Med 41:e457-465. https://doi.org/10.1097/CCM.0b013e3182a63b5d

Fabry B, Maksym GN, Butler JP, Glogauer M, Navajas D, Fredberg JJ (2001) Scaling the microrheology of living cells. Phys Rev Lett 87:148102. https://doi.org/10.1103/PhysRevLett.87.148102

Fabry B, Maksym GN, Butler JP, Glogauer M, Navajas D, Taback NA, Millet EJ, Fredberg JJ (2003) Time scale and other invariants of integrative mechanical behavior in living cells. Phys Rev E Stat Nonlinear Softw Matter Phys 68:041914. https://doi.org/10.1103/ PhysRevE.68.041914

Féréol S, Fodil R, Labat B, Galiacy S, Laurent VM, Louis B, Isabey D, Planus E (2006) Sensitivity of alveolar macrophages to substrate mechanical and adhesive properties. Cell Motil Cytoskeleton 63:321-340. https://doi.org/10.1002/cm.20130

Féréol S, Fodil R, Laurent VM, Balland M, Louis B, Pelle G, Henon S, Planus E, Isabey D (2009) Prestress and adhesion site dynamics control cell sensitivity to extracellular stiffness. Biophys J 96:2009-2022. https://doi.org/10.1016/j.bpj.2008.10.072

Foster KA, Oster CG, Mayer MM, Avery ML, Audus KL (1998) Characterization of the A549 cell line as a type II pulmonary epithelial cell model for drug metabolism. Exp Cell Res 243:359366. https:// doi.org/10.1006/excr.1998.4172

Hirschl RB, Pranikoff T, Gauger P, Schreiner RJ, Dechert R, Bartlett RH (1995) Liquid ventilation in adults, children, and full-term neonates. Lancet 346:1201-1202

Ingber DE (2008) Tensegrity-based mechanosensing from macro to micro. Prog Biophys Mol Biol 97:163-179. https://doi.org/10. 1016/j.pbiomolbio.2008.02.005

Ingber DE, Wang N, Stamenović D (2014) Tensegrity, cellular biophysics, and the mechanics of living systems. Rep Prog Phys 77(4):046603 (Review)

Isabey D, Féréol S, Caluch A, Fodil R, Louis B, Pelle G (2013) Force distribution on multiple bonds controls the kinetics of adhesion in stretched cells. J Biomech 46:307-313. https://doi.org/10.1016/j. jbiomech.2012.10.039

Isabey D, Pelle G, Andre Dias S, Bottier M, Nguyen NM, Filoche M, Louis B (2016) Multiscale evaluation of cellular adhesion alteration and cytoskeleton remodeling by magnetic bead twisting. Biomech Model Mechanobiol 15:947-963. https://doi.org/10. 1007/s10237-015-0734-5

Kawkitinarong K, Linz-McGillem L, Birukov KG, Garcia JG (2004) Differential regulation of human lung epithelial and endothelial barrier function by thrombin. Am J Respir Cell Mol Biol 31:517527. https://doi.org/10.1165/rcmb.2003-0432OC

Kissa E (1994) Fluorinated surfactants: synthesis properties applications, pp. vii +469 . Ed. Marcel Dekker Inc., New York. ISBN $0-8247-9011-1$

Krafft MP (2001) Fluorocarbons and fluorinated amphiphiles in drug delivery and biomedical research. Adv Drug Deliv Rev 47:209228

Martins MdF, Abairos V (2002) Glycocalyx of lung epithelial cells. Int Rev Cytol 216. https://doi.org/10.1016/s0074-7696(02)16005-0

Ohayon J, Tracqui P, Fodil R, Féréol S, Laurent VM, Planus E, Isabey D (2004) Analysis of nonlinear responses of adherent epithelial cells 
probed by magnetic bead twisting: a finite element model based on a homogenization approach. J Biomech Eng 126:685-698

Pathak A, Deshpande VS, McMeeking RM, Evans AG (2008) The simulation of stress fibre and focal adhesion development in cells on patterned substrates. J R Soc Interface 5:507-524. https://doi.org/ 10.1098/rsif.2007.1182

Rai S, Nejadhamzeeigilani Z, Gutowski NJ, Whatmore JL (2015) Loss of the endothelial glycocalyx is associated with increased E-selectin mediated adhesion of lung tumour cells to the brain microvascular endothelium. J Exp Clin Cancer Res 34:105. https:// doi.org/10.1186/s13046-015-0223-9

Riess JG (1994) Highly fluorinated systems for oxygen transport, diagnosis and drug delivery. Coll Surf A Physicochem Eng Asp 84:33-48. https://doi.org/10.1016/0927-7757(93)02696-C

Riess JG, Krafft MP (1997) Advanced fluorocarbon-based systems for oxygen and drug delivery, and diagnosis. Artif Cells Blood Substit Immobil Biotechnol 25:43-52

Sen CK (2009) Wound healing essentials: Let there be oxygen. Wound Repair Regen. Official Publication of the Wound Healing Society [and] the European Tissue Repair Society. doi:10.1111/j.1524475X.2008.00436.X

Stamenović D, Fredberg JJ, Wang N, Butler JP, Ingber DE (1996) A microstructural approach to cytoskeletal mechanics based on tensegrity. J Theor Biol 181(2):125-36. https://doi.org/10.1006/ jtbi. 1996.0120

Swain RJ, Kemp SJ, Goldstraw P, Tetley TD, Stevens MM (2010) Assessment of cell line models of primary human cells by Raman spectral phenotyping. Biophys J 98:1703-1711. https://doi.org/10. 1016/j.bpj.2009.12.4289

Thi MM, Tarbell JM, Weinbaum S, Spray DC (2004) The role of the glycocalyx in reorganization of the actin cytoskeleton under fluid shear stress: a "bumper-car" model. Proc Natl Acad Sci USA 101:16483-16488. https://doi.org/10.1073/pnas.0407474101
Tooley R, Hirschl RB, Parent A, Bartlett RH (1996) Total liquid ventilation with perfluorocarbons increases pulmonary end-expiratory volume and compliance in the setting of lung atelectasis. Crit Care Med 24:268-273

Trepat X, Grabulosa M, Puig F, Maksym GN, Navajas D, Farre R (2004) Viscoelasticity of human alveolar epithelial cells subjected to stretch. Am J Physiol Lung Cell Mol Physiol 287:L1025-1034. https://doi.org/10.1152/ajplung.00077.2004

Varani J, Hirschl RB, Dame M, Johnson K (1996) Perfluorocarbon protects lung epithelial cells from neutrophil-mediated injury in an in vitro model of liquid ventilation therapy. Shock 6:339-344

Wang N, Butler J, Ingber D (1993) Mechanotransduction across the cell surface and through the cytoskeleton. Science 260:1124-1127. https://doi.org/10.1126/science.7684161

Wang N, Tolic-Norrelykke IM, Chen J, Mijailovich SM, Butler JP, Fredberg JJ, Stamenović D (2002) Cell prestress. I. Stiffness and prestress are closely associated in adherent contractile cells. Am J Physiol Cell physiol 282:C606-616. https://doi.org/10.1152/ ajpcell.00269.2001

Wemhöner A, Hackspiel I, Hobi N, Ravasio A, Haller T, Rüdiger M (2010) Effects of Perfluorocarbons on surfactant exocytosis and membrane properties in isolated alveolar type II cells. Respir Res 11:1-12. https://doi.org/10.1186/1465-9921-11-52

Wesseler EP, Iltis R, Clark LC (1977) The solubility of oxygen in highly fluorinated liquids. J Fluor Chem 9:137-146

Yao Y, Rabodzey A, Dewey CF (2007) Glycocalyx modulates the motility and proliferative response of vascular endothelium to fluid shear stress. Am J Physiol Heart Circulatory Physiol 293:H1023-H1030. https://doi.org/10.1152/ajpheart.00162.2007 